\title{
Classroom Walls and City Hall: Mobilizing Local Partnerships to Advance the Sustainable Development Agenda
}

\author{
Gaea Morales ${ }^{1, *}$, Erin Bromaghim ${ }^{2}$, Angela Kim ${ }^{2}$, Caroline Diamond ${ }^{3}$, Alejo Maggini ${ }^{3}$, Avery Everhart ${ }^{1}$, \\ Sofia Gruskin ${ }^{4}$ (D) and Anthony Tirado Chase ${ }^{3}$ \\ 1 Dana and David Dornsife College of Letters, Arts and Sciences, University of Southern California, \\ Los Angeles, CA 90089, USA; everhart@usc.edu \\ 2 Mayor's Office of International Affairs, Los Angeles, CA 90012, USA; erin.bromaghim@lacity.org (E.B.); \\ angela.kim@lacity.org (A.K.) \\ 3 John Parke Young Initiative on the Global Political Economy, Occidental College, Los Angeles, CA 90041, \\ USA; cdiamond@oxy.edu (C.D.); amaggini@oxy.edu (A.M.); achase@oxy.edu (A.T.C.) \\ 4 Institute on Inequalities in Global Health, University of Southern California, Los Angeles, CA 90033, USA; \\ gruskin@med.usc.edu \\ * Correspondence: gaeapatr@usc.edu
}

Citation: Morales, G.; Bromaghim, E.; Kim, A.; Diamond, C.; Maggini, A.; Everhart, A.; Gruskin, S.; Chase, A.T. Classroom Walls and City Hall: Mobilizing Local Partnerships to Advance the Sustainable Development Agenda. Sustainability 2021, 13, 6173. https://doi.org/ $10.3390 /$ su13116173

Academic Editors: Aurélien Decamps, Benoit Martimort-Asso and Carine Royer

Received: 31 March 2021

Accepted: 24 May 2021

Published: 31 May 2021

Publisher's Note: MDPI stays neutral with regard to jurisdictional claims in published maps and institutional affiliations.

Copyright: (c) 2021 by the authors. Licensee MDPI, Basel, Switzerland. This article is an open access article distributed under the terms and conditions of the Creative Commons Attribution (CC BY) license (https:/ / creativecommons.org/licenses/by/ $4.0 /)$.

\begin{abstract}
This roundtable discussion raises and responds to the question: What can be learned from academic and local government partnerships to advance the Sustainable Development Goals (SDGs)? We draw on several years of cooperation between the Office of the Mayor of Los Angeles (CA, USA) and academic institutions on how to best advance and integrate the United Nations' SDGs into policy. Stakeholders from this project give voice to varying perspectives across roles-as city officials, academic partners, graduate and undergraduate students-in the Los Angeles case of SDG implementation. The article outlines a "Task Force" model, under the joint facilitation of faculty advisors and guidance of city partners, that promotes students' experiential learning, and meaningfully bridges theory and practice in bringing global frameworks to local practice. We highlight what we gain by disaggregating the local and taking space and place seriously in sustainability policy, while underscoring the importance of long-term trust and relationship building in the success of local sustainability efforts.
\end{abstract}

Keywords: sustainable development; SDGs; city-academic partnerships; global-local policy making

\section{Introduction \\ Gaea Morales}

The element of "partnerships" and the importance of inter-institutional, cross-sector approaches are at the heart of the United Nations' 2030 Sustainable Development Agenda and its message to "leave no one behind". Scholars and practitioners alike have come to understand that global vision requires local action, and that international organizations may benefit from partnering with schools and academic universities [1]. However, there is still more to be learned about how this plays out in the local or urban context and with its community of actors, particularly how local government and higher educational institutions (HEIs) can best work together to advance sustainable change.

Therefore, we ask: What can be learned from academic and local government partnerships to advance the Sustainable Development Goals? In the spirit of the question, we bring together perspectives from local government, academic institutions, and students in the Los Angeles (L.A.) case [2]. This roundtable approach serves to magnify the innovative practice of public and academic sectors' (who) collaboration (what) in efforts to advance sustainable development (how). It draws from an ongoing partnership between the City of Los Angeles Mayor's Office of International Affairs (MOIA) and academic institutions in and working in Los Angeles on efforts to localize the United Nations Sustainable Development Goals 
(SDGs) [3]. The purpose of this roundtable is two-fold: (1) to highlight the ways in which sustainable development, as a common, unifying goal, can yield diverse outcomes and benefits for all those involved in the local context; and (2) to provide a case or model of public-academic partnership in implementing the SDGs. On the latter point, we hope that the lessons brought to bear in this discussion can serve as a model for other cities seeking to advance sustainable development.

Academic advisors and students have worked over several years to support L.A. city efforts to adopt, translate, and mobilize around the sustainable development agenda in order to both inform local governance and better serve communities. Common among these projects is a "Task Force" structure, or student consultant groups consisting of undergraduate and graduate students, working under the guidance or facilitation of an academic advisor and in close communication with city partners (from MOIA and/or other departments and offices). These projects are either conducted within the semester, as a registered course, or over the summer as a university-sponsored internship, under the direct supervision of MOIA. Within the larger SDG agenda, projects have ranged from broad efforts to identify and engage with key stakeholders within civil society, to research teams working directly with city departments on issues of poverty, climate change, homelessness, and gender equity. The experiences represented in this roundtable draw from a number of different project phases. City and academic partners possess a biggerpicture or long-term view perspective given their involvement in various phases since the end of 2017, while students were asked to speak to the projects in which they have been or are currently involved.

The issues addressed by these Task Forces require multi-dimensional action, and drawing on local and global lessons alike. By centering on the lessons to be drawn from partnerships, we make connections among conversations on sustainability in academia and curricula [4], sustainability policy in the immediate city context in which universities operate [5], and in the broader global network of cities working towards a more sustainable future [6]. The partnerships forged here build inter-institutional trust and enable the development of personal and professional connections that go beyond the work on individual projects. What we have learned, and what we hope to demonstrate through this roundtable, is that when we work together, we are able to generate locally owned, locally driven change that serves not only individual experience and growth, but also pedagogical and administrative goals in support of the sustainable development agenda.

\section{Literature Review and Approach}

Our work together bridges multiple disciplinary themes and approaches, linking sustainability science, education, politics, and urban affairs. There is a rich and thriving literature in urban studies on local sustainability initiatives, with attention to the role of local governments [7-9] and academic institutions [10-12] in sustainability efforts vis à vis national governments and wider regional efforts. Delving more deeply at the urban level, scholars have highlighted the importance of collaborative and participatory avenues, such as via citizen science [13] (or, "community-generated data"), for successful and responsive sustainability programming $[14,15]$. Meanwhile, sustainability education scholars have demonstrated cases and models of integrating sustainability, from within classroom curricula and research agendas $[16,17]$, to academic programming $[18,19]$ and broader institutional and systemic reforms [20-22].

These works have provided needed insights into the higher conceptual and framework levels of sustainable development initiatives, as well as approaches to achieving environmental and broader sustainability outcomes. There is, however, more limited research on how partnership models work in practice, and what value different participants bring and can gain from working together to advance sustainable development. Our research therefore responds directly to a call for a greater understanding of "the relationship between cities [and] universities and [the nature of] local sustainability efforts" [23] (p. 695). We, as participants in the process, focus on the context of a single city case-Los Angeles-and 
provide descriptive support for the ways in which local collaboration, particularly across local government and academic institutions, can both support innovative policy making in the realm of sustainable development, and advance sustainability education and training. In its three years, the L.A. SDGs initiative has involved eight city teams (departments and Mayor's shops, including the Mayor's Office of International Affairs), 13 academic advisors, and 162 undergraduate and graduate students across five universities (such as Occidental College and the University of Southern California). Participants for this roundtable consist of select representative perspectives from the city, academic institutions, and student task forces. Those included here have had engagement in at least two if not more of the task forces and can therefore speak directly to personal experiences and lessons learned over the years. More precisely, each stakeholder in the roundtable is responding to the question: What can be learned from academic and local government partnerships to advance the Sustainable Development Goals (SDGs)? In doing so, we not only provide experiential evidence on the value of local government and academic partnerships, but also a working model that we hope will inspire other cities and institutions to collaborate.

\section{Roundtable (Results)}

\subsection{How University Partnerships Help Cities Achieve Sustainable Development} Erin Bromaghim and Angela Kim (City Partners)

City governments deliver critical services every day. From transportation and sanitation to COVID-19 testing and vaccination, local governments continually innovate to meet the needs of residents, with far fewer resources than regional, state, or national governments. In the City of Los Angeles, partnerships strengthen the work we do, including working closely with colleges and universities to advance the Sustainable Development Goals (SDGs). Over three years, the city has worked with more than 160 undergraduate and graduate students as interns, members of faculty-led task forces, and as full-time consultants on projects that advance sustainable development at the local level. Bringing students into our work on the SDGs helps us tap into their perspectives as members of the community, test new ideas, and bring their research and recommendations into practice.

Realizing the SDGs depends on translating big, global problems into solutions that work in the context of our own communities, leveraging existing structures through a sustainable development lens. Additionally, in our experience, the most successful student projects are often narrowly focused. Rather than asking "How can a city achieve SDG 11?", we bring students, faculty members, and our city colleagues together to ask hyperlocal questions like "How can L.A.'s Bureau of Street Services plan to more equitably deliver street assets like bus shelters and street sweeping?". Or, instead of asking "How can the city achieve SDG 16?", students focus on "How can we increase accessibility of youth services through investments in public transit and online offerings?" Answering these questions requires defining terms and stakeholders, understanding the underlying processes, and identifying constraints-all outputs that create additional value in themselves.

Brokering these relationships and refining these projects between our academic partners and city colleagues take time and trust. Each project is the product of one-to-one relationship building to create a focused effort that delivers value to the city as well as a worthwhile experience for the students. A summer or a semester moves quickly, but beyond their immediate project outputs, the students also contribute new methodologies and ideas that grow our understanding of sustainable development in action. Additionally, most often students look to other cities, not international development organizations or national governments, to surface what works. Finding these examples creates space for accountability and experimentation, where students can ask why and what would be required to drive similar progress in L.A. These questions give students an opportunity to better understand our local context, and give us the opportunity to invite new perspectives into the city's programs, policies, and operations. Sustainable development is a means to achieve the world we want, and the SDGs define that world with clear, specific goals. 
Our academic partnerships bring the same type of focus to the process of sustainable development in Los Angeles, creating lasting value and true collective impact.

\subsection{Humanizing the SDGs: Student Empowerment to Advance the 2030 Agenda Caroline Diamond and Alejo Maggini (Undergraduate Students)}

We bring ourselves to the process of localizing the UN Sustainable Development Goals-our homes, our experiences, and our identities ground how we think about the SDGs and help us to imagine their potential-in Los Angeles and beyond. We are both undergraduate students majoring in International Relations and Economics at Occidental College in Northeast Los Angeles. One of us is from Portland, Oregon and the other is from Mendoza, Argentina. Growing up in places other than Los Angeles, but working with the city, has given us the opportunity to immerse ourselves in the complex local history of L.A., while bringing pieces of our homes to our work.

Together, we have engaged in four separate Task Force projects, covering themes of peace and justice in Youth Source Centers in Los Angeles (SDG 16), intergenerational poverty and education (SDGs 1, 4), LGBTQIA+ data disaggregation (SDG 5), and transformative justice in an L.A.-based truth telling process (SDGs 10,16). Looking back on our experience as Task Force members and more recently as supervisors, we have four main takeaways from our work on SDG localization: the importance of student excitement and buy-in, the possibility for co-learning and relationship building (like this roundtable), the application of an experiential learning model, and the potential to humanize the SDGs.

(a) Students must believe in the mission of the SDGs to be passionate actors and advocates for their localization. In every project, our lived experiences, academic interests, and passions play a crucial role in shaping creative ways to achieve the SDGs. This spring semester, our common interests in restorative justice, community activism, and peacebuilding led to a project titled "From Truth and Reconciliation to Transformative Justice in L.A." With this project, we have delved into the intersections of conflict resolution and government responsibility, while centering racial justice and community healing. We feel committed to SDG localization because we had the opportunity to shape this process with our varied interests and expertise.

(b) We cherish the relationships we have built with our student colleagues, faculty supervisors, and government officials. These relationships are founded on the belief that all of us are valuable to a conversation around SDG localization. We find that this level of collaboration is non-existent in most academic spaces. Working across professional sectors and education levels has expanded the depth of our research-combining knowledge of institutional history, past and present literature, grassroots movements and policy initiatives, and lived experience of the inequalities the SDGs address.

(c) Student-driven SDG research is experiential in nature. Experiential learning is a powerful path for undergraduate students to apply theoretical frameworks to the real world. Task Forces, unlike traditional internships, invite students to shape their working environment, express their aspirations, and assume full responsibility for their deliverables. In summer 2020, we completed separate projects with the Mayor's Office of International Affairs and the Mayor's Office of Economic Opportunity. Our final deliverables were the culmination of extensive quantitative and qualitative research, and the process itself provided valuable insight into transforming findings into engaging visuals and actionable recommendations.

(d) We believe in bringing the SDGs to the human level—one based on diversity, lived experience, and restorative practices. Task Forces become spaces for knowledge sharing and community building where we can shift our positions as "students" and "supervisors" to partners working to achieve the SDGs. Being able to voice our ideas with experts and public servants affirms that our background and experiences belong in these environments. The Task Force model and SDG partnerships have allowed us to express creative solutions for real world problems-showing that the ability to 
"do well" in class is not the only thing that matters in the academic sphere. We can be passionate activists for SDGs beyond our status as students.

3.3. Academic-Government Partnerships Offer Unique Opportunities for Graduate Students to Professionalize

Avery Everhart (PhD Candidate)

I served as both an academic advisor to a team of graduate and undergraduate students, and as their technical expert and team leader for a project on equity in access to transportation infrastructure with the SDG Leadership Academy. Serving in both roles while being a PhD candidate myself was an edifying and eye-opening experience about the possibilities of academic-government collaborations and what they can accomplish to realize the SDGs.

As an advisor, I relished the opportunity to give students hands-on experience working with geographic information science (GIS) to address social, spatial, and racial inequities in direct collaboration with local government. This type of experience cannot be easily recreated in the typical classroom or the typical GIS lab. Additionally, even further, most GIS lab-based courses rely on hyper cleaned and prepared data to teach spatial science. However, in the real world, data, and indeed the working conditions, can be messy. Working with our local government enabled us to produce a functional technical product in a cost-effective way. Moreover, this collaboration enabled my team of undergraduate and graduate students to learn how to negotiate deliverables, work with real world data on real world problems, and put their training to good use in helping to realize the SDGs locally. This kind of hands-on experience is invaluable for students and programs like this partnership help government offices to kick start projects that may otherwise never get off the ground.

As a student, it was an exceptionally gratifying project because all of the things I was able to teach my students as their advisor, I also learned. It was one of the first times I had negotiated on the scope of projects and was a completely different experience from my usual teaching and research assistantship work as a doctoral student. Further, partnering with local government also gave me access to data and information that I would never have gotten otherwise. My team and I gained insights into everything from how policy decisions related to city planning are made to the challenges local governments face in addressing historic inequalities even where there is energy and political will to fix those issues. We had anticipated that our government partners may be hesitant to stare down the hard truths of inequality in the city, but we were pleasantly surprised that they wanted us to hold them accountable to the data and to our mandate in the SDGs. In fact, this kind of collaboration requires transparency and accountability, and because of the rapport I and my team established with our city partners, we were able to put forth a realistic path to redressing the inequities we discovered. At the same time, I personally gained indispensable experience in working on global initiatives in a local way that I will bring with me after the doctorate, whether I enter the professoriate, the non-profit or charitable sector, or even government.

\subsection{Cooperative Policy Making: Learning by Doing \\ Sofia Gruskin and Anthony Tirado Chase (Academic Advisors)}

True academic partnerships with local governments might seem a pipe dream. However, when they work, they can expand education beyond the limits of what many students and teachers dream is possible from within the traditional classroom bubble. We both regularly run "Student Task Forces" that support the Mayor's office in its work to integrate the UN's Sustainable Development Goals into concrete city policy, and within a range of issues areas. The students who have constituted the dozen or so distinct Task Forces we have helped oversee to date have been active participants in shaping the scope and approach to each project, learning by doing, requiring them to both master academic material and to deal with the opportunities and constraints of city structures. When it works, it is because 
of strong engagement from city partners and, equally important, engaged students who are able to accept shifting goal posts and other changes beyond any one person's control.

This type of work has, to be sure, many moments of frustration. However, frustrations that result from being active players in real-world programming and policy making are precisely what can move students (and professors!) beyond the abstract and into the complexities of practice that can only be imagined from a college campus. This partnership experience highlights the importance of relationship building and trust, and the need to be not just creative but flexible in dealing with multiple real-world stakeholders. The realities of what it takes to collaboratively create a quality set of implementable policy suggestions are far different than assumptions from inside a classroom. By moving from consumers of knowledge into producers of knowledge, students are not only mastering academic ideas but how to make them matter in the world. These are not just learning experiences for students; we struggle together with the challenges and lessons of translating theory into local-level practice.

We both remain committed to this model because, to put it simply, it works. It works to expand learning in radically new ways. Additionally, it works to help us all-professors and students and city officials-contribute to our city, our communities, and to stimulate processes that create sustainable, systemic change. The longer we all work together, the more our institutions and the city are able to build depth and breadth in our collective action—all based on our shared commitment to sustainability.

\section{Discussion}

\section{Gaea Morales}

This roundtable is testament to both the ways in which different stakeholders have benefited and grown from these partnerships, and how these partnerships have enabled broad sustainability endeavors to become realized (or localized) over time. We highlight the following action-oriented themes and takeaways.

The power of experiential learning: All stakeholders speak to how these projects, in which students lead and/or participate in Task Forces, allow for unique hands-on training and experiences. Students learn directly from public servants, and are able to strengthen their project management and communication skills in government settings. They also have the opportunity to apply and further enrich their identities and intellectual capacity, regardless of their academic level—from sophomores and juniors studying diplomacy and restorative justice practices to an advanced $\mathrm{PhD}$ candidate with expertise in spatial sciences and global health. When students feel that their voices matter, and when we take their data-driven recommendations seriously, they are empowered beyond the scope of their projects to pursue sustainability and its cross-cutting issues in their future studies and career paths. Over time, these projects transform the ways in which students think about what sustainability means and looks like, and what this then means for how they can play an active role in its implementation within and beyond academia.

Access and accountability: On another level, these partnerships bring to light the ways in which city officials may hold themselves accountable to addressing systemic issues central to achieving sustainable development. All stakeholders recognize that the sustainable development agenda speaks to a wide variety of intersectional equity issues, especially when magnifying the local level. Promoting projects under the banner of sustainable development requires a systemic reckoning with what sustainability means at the institutional level and how to address and transform city-wide infrastructures. Insights from academic partners and students can further such efforts to think critically and holistically about how we define, envision, and realize sustainability. On a logistical level, the accessibility of data and information, especially regarding these efforts, is one step in that direction. It promotes a higher level of transparency and builds trust, not just in the generation of deliverables and recommendations, but also for longer-term efforts to involve and inform the community about city sustainability initiatives. 
Translation as bridging theory and practice: Academic and city partners both highlight the work of translation: of taking a city initiative to the classroom, a lofty goal to the local context, or a broad objective to a narrow question. These projects are a way to bring the "real world" into teaching by allowing students to draw connections between academic literature and policy and government decision making - even where material is new or unfamiliar. It makes the "so what?" of research tangible, and places concepts and theories in context. As a result, students are enabled to be both producers of knowledge and to be community liaisons, aware of their positions both as students and as members of the community. Emphasizing positionality and context also allows for narrower, more actionable questions and approaches to lofty goals within local realities that were initially envisioned for national government. As stakeholders work together, bridging city experiences and goals, academic expertise, and student passion, we are able to translate dimensions of the sustainable agenda in ways that are meaningful to the specific context of L.A. and its communities. Looking outwards, universities and colleges also bring important insight into the broader network in which cities exist. As highlighted by city partners, students are able to shed light on best practices and lessons from other cities globally.

Highlighting the city ecosystem: Neither the nation state nor the city is a monolith-a lesson students come to learn throughout the process as they work across city departments and commissions, speak to and hear from different officials, and think through the systems requiring innovation and external perspectives and insights. Cities consist of various institutions, industries, communities, public and private actors-each with potentially aligned or conflicting priorities and interests. The importance of disaggregation becomes clear through the partnership: disaggregation of the cityscape, of the themes and issues of concern, of objectives and goals. For instance, we cannot talk about issues of climate action and environmental protection in the city of Los Angeles without talking about the city's long history of inequality in planning and infrastructure that disproportionately burdens and harms communities of color. The city is in constant interaction with its constituents. Community building and fostering relationships (including, but not limited to, colleges and universities), therefore, are at the heart of sustainability efforts. Understanding the complex ecosystem of actors and overlapping issue areas at the local level is central to city efforts to implement sustainability.

The time horizon, investments, and gains: While our hope is to highlight the benefits of such partnerships, we also want to communicate the challenges to be overcome. These partnerships require different forms and degrees of investment, and gains increase over time. Academic advisors devote their expertise and energy to communicate with city partners and manage and guide students towards relevant resources and materials. City partners also invest a significant amount of time to communicate evolving project plans for the duration of a project, and over semesters and summers provide even more hands-on management. It is also a reality that some cohorts do not see the fruits of their labor until months after their official part in the process ends. While projects may run for short periods (summer months or semesters), it is important for all concerned not to lose sight of the big picture. All the projects to date are connected and have built on lessons learned from each student consultant cohort. The landscape analyses of earlier phases inform the sectors and communities for outreach, and areas for mobilization that are most urgent and with which the city can have most traction such as climate action and homelessness. The first ever Voluntary Local Review [24] was in part informed by the deliverables of early cohorts working to understand what goals and indicators applied (or could be applied) to the Los Angeles context. Additionally, while results take time, what grows exponentially is a community of government partners, academic institutions, and students, all linked by a shared vision of sustainable development—both local and global.

There is consensus in the literature that stakeholder commitment and buy-in are required for sustainable change, and that participatory decision making as well as collaboration allows not only for greater representation and policy responsiveness, but also more innovative and transformative approaches. Our experience not only supports these 
findings, but also provides a working model and key lessons for students and faculty in HEIs and those working within local government structures.

\section{Conclusions \\ Gaea Morales}

We hope not only to claim that education and sustainability are intertwined, but also to demonstrate that sustainability education is intertwined with place. Understanding the complex micro-level ecosystem of a given context, in order to advance sustainability efforts, requires forging and then leveraging multi-sector partnerships within a given place. We can build continuity in sustainability efforts not just across academic degrees, but also by providing students with applied, hands-on research work. Students learn and grow as both budding intellectuals and practitioners, and more advanced students gain hands-on training on project and research management in a professional capacity. These experiences can foster critical paradigm shifts in how students perceive their role and place in broader, global sustainability efforts. As a space for learning and intellectual exchange, academic institutions serve as rich sources for innovative research and energy, for faculty experts and students alike. Academic advisors lead by example in their ability to engage and facilitate academic discourse in ways that directly inform student projects. Cities provide hands-on professionalization opportunities that support broader system-wide initiatives to promote sustainability.

The model presented in the roundtable through the lens of various stakeholders-city leaders, academic advisors, and graduate and undergraduate students-suggests that there is synergy between what cities hope for their residents, what universities desire for their students, and what students aspire to for their futures. Additionally, this is not unique to Los Angeles. It is our hope that practitioners and scholars alike may glean lessons from the L.A. case, in order to highlight the role of the local level—particularly local partnerships-in advancing the global sustainable development agenda.

Author Contributions: Introduction, Literature Review, Discussion, and Conclusion, G.M.; Roundtable (qualitative data), E.B., A.K., C.D., A.M., A.E., S.G., and A.T.C. All authors were involved in the writing and revision process. All authors have read and agreed to the published version of the manuscript.

Funding: This research received no external funding.

Institutional Review Board Statement: Not applicable.

Informed Consent Statement: Written informed consent has been obtained from the participants to publish this paper.

Acknowledgments: We would like to recognize 162 undergraduate and graduate students, 13 academic advisors, five universities, and eight City of Los Angeles offices and departments that have come together to bring over three years of work to fruition. We would also like to thank Sanjeev Khagram, the Mayor's Fund for Los Angeles, and the Conrad N. Hilton Foundation for their partnership and support.

Conflicts of Interest: The authors declare no conflict of interest.

\section{References}

1. Higher Education Sustainability Initiative. Available online: https://sdgs.un.org/topics/education/hesi (accessed on 31 March 2021).

2. Los Angeles Sustainable Development Goals. Los Angeles Mayor's Office. Available online: https://sdg.lamayor.org/ (accessed on 31 March 2021).

3. United Nations-Department of Economic and Social Affairs. "The 17 Goals". United Nations. Available online: https: / /sdgs.un.org/goals (accessed on 31 March 2021).

4. Education and Academia-What Is the Education and Academia Stakeholder Group (EASG)? Available online: https:// sustainabledevelopment.un.org/majorgroups/educationandacademia (accessed on 31 March 2021).

5. Local Leadership on the Sustainable Development Goals (Project). Available online: https://www.brookings.edu/project/localleadership-on-the-sustainable-development-goals/ (accessed on 31 March 2021).

6. Sustainable Cities: Inclusive, Resilient and Connected. Available online: https:/ / www.unsdsn.org/ cities (accessed on 31 March 2021). 
7. Atkinson, D. Local Government, Local Governance and Sustainable Development: Getting the Parameters Right; Human Sciences Research Council Publishers: Cape Town, South Africa, 2002.

8. Brugmann, J. Planning for Sustainability at the Local Government Level. Environ. Impact Assess. Rev. 1996, 16, 363-379. [CrossRef]

9. Saha, D.; Paterson, R.G. Local Government Efforts to Promote the 'Three Es' of Sustainable Development. J. Plan. Educ. Res. 2008, 28. [CrossRef]

10. Leal Filho, W.; Vargas, V.R.; Salvia, A.L.; Brandli, L.L.; Pallant, E.; Klavins, M.; Ray, S.; Moggi, S.; Maruna, M.; Conticell, E.; et al. The Role of Higher Education Institutions in Sustainability Initiatives at the Local Level. J. Clean. Prod. 2019, 233, $1004-1015$. [CrossRef]

11. Findler, F.; Schönherr, N.; Lozano, R.; Reider, D.; Martinuzzi, A. The Impacts of Higher Education Institutions on Sustainable Development: A Review and Conceptualization. Int. J. Sustain. High. Educ. 2019, 20, 23-38. [CrossRef]

12. Zilahy, G.; Huisingh, H. The Roles of Academia in Regional Sustainability Initiatives. J. Clean. Prod. 2009, 17, 1057-1066. [CrossRef]

13. Shulla, K.; Leal Filho, W.; Sommer, J.H.; Salvia, A.L.; Borgemeister, C. Channels of Collaboration for Citizen Science and the Sustainable Development Goals. J. Clean. Prod. 2020, 264, 121735. [CrossRef]

14. Bhatta, T.P. Local Development Plan: An Avenue for University-Local Government-Community Collaboration for Sustainable Community Development. J. Educ. Res. 2018, 7, 36-51. [CrossRef]

15. Meyer, J.; Mader, M.; Zimmermann, F.; Çabiri, K. Training Sessions Fostering Transdisciplinary Collaboration for Sustainable Development: Albania and Kosovo Case Studies. Int. J. Sustain. High. Educ. 2017, 18, 738-757. [CrossRef]

16. Lozano García, F.J.; Kevany, K.; Huisingh, D. Sustainability in Higher Education: What Is Happening? J. Clean. Prod. 2006, 14, 757-760. [CrossRef]

17. Stough, T.; Ceulemans, K.; Lambrechts, W.; Cappuyns, V. Assessing Sustainability in Higher Education Curricula: A Critical Reflection on Validity Issues. J. Clean. Prod. 2018, 172, 4456-4466. [CrossRef]

18. Antó, J.M.; Martí, J.L.; Casals, J.; Bou-Habib, P.; Casal, P.; Fleurbaey, M.; Frumkin, H.; Jiménez-Morales, M.; Jordana, J.; Lancelotti, C.; et al. The Planetary Wellbeing Initiative: Pursuing the Sustainable Development Goals in Higher Education. Sustainability 2021, 13, 3372. [CrossRef]

19. Braßler, M.; Sprenger, S. Fostering Sustainability Knowledge, Attitudes, and Behaviours through a Tutor-Supported Interdisciplinary Course in Education for Sustainable Development. Sustainability 2021, 13, 3494. [CrossRef]

20. Leal Filho, W.; Raath, S.; Lazzarini, B.; Vargas, V.R.; de Souza, L.; Anholon, R.; Quelhas, O.L.G.; Haddad, R.; Klavins, M.; Orlovic, V.L. The Role of Transformation in Learning and Education for Sustainability. J. Clean. Prod. 2018, 199, 286-295. [CrossRef]

21. Lozano, R.; Lukman, R.; Lozano, F.J.; Huisingh, D.; Lambrechts, W. Declarations for Sustainability in Higher Education: Becoming Better Leaders, through Addressing the University System. J. Clean. Prod. 2013, 48, 10-19. [CrossRef]

22. Yarime, M.; Trencher, G.; Mino, T.; Scholz, R.W.; Olsson, L.; Ness, B.; Frantzeskaki, N.; Rotmans, J. Establishing Sustainability Science in Higher Education Institutions: Towards an Integration of Academic Development, Institutionalization, and Stakeholder Collaborations. Sustain. Sci. 2012, 7, 101-113. [CrossRef]

23. Opp, S.M.; Saunders, K.L. Pillar Talk: Local Sustainability Initiatives and Policies in the United States-Finding Evidence of the 'Three E's': Economic Development, Environmental Protection, and Social Equity. Urban Aff. Rev. 2013, 49, 678-717. [CrossRef]

24. Voluntary Local Review. Los Angeles Mayor's Office. Available online: https://sdg.lamayor.org/voluntary-local-review (accessed on 31 March 2021). 